\title{
Technical note: The silicon isotopic composition of choanoflagellates: implications for a mechanistic understanding of isotopic fractionation during biosilicification
}

\author{
Alan Marron ${ }^{1}$, Lucie Cassarino ${ }^{2}$, Jade Hatton ${ }^{2}$, Paul Curnow ${ }^{3}$, and Katharine R. Hendry ${ }^{2}$ \\ ${ }^{1}$ Department of Plant Sciences, University of Cambridge, Downing St, Cambridge, CB2 3EA, UK \\ ${ }^{2}$ School of Earth Sciences, University of Bristol, Wills Memorial Building, Queen's Road, Bristol, BS8 1RJ, UK \\ ${ }^{3}$ School of Biochemistry, University of Bristol, Biomedical Sciences Building, University Walk, Bristol, BS8 1TD, UK
}

Correspondence: Katharine R. Hendry (k.hendry@bristol.ac.uk)

Received: 10 May 2019 - Discussion started: 12 June 2019

Revised: 19 November 2019 - Accepted: 21 November 2019 - Published: 17 December 2019

\begin{abstract}
The marine silicon cycle is intrinsically linked with carbon cycling in the oceans via biological production of silica by a wide range of organisms. The stable silicon isotopic composition (denoted by $\delta^{30} \mathrm{Si}$ ) of siliceous microfossils extracted from sediment cores can be used as an archive of past oceanic silicon cycling. However, the silicon isotopic composition of biogenic silica has only been measured in diatoms, sponges and radiolarians, and isotopic fractionation relative to seawater is entirely unknown for many other silicifiers. Furthermore, the biochemical pathways and mechanisms that determine isotopic fractionation during biosilicification remain poorly understood. Here, we present the first measurements of the silicon isotopic fractionation during biosilicification by loricate choanoflagellates, a group of protists closely related to animals. We cultured two species of choanoflagellates, Diaphanoeca grandis and Stephanoeca diplocostata, which showed consistently greater isotopic fractionation (approximately $-5 \%$ o to $-7 \%$ ) than cultured diatoms $(-0.5 \%$ to $-2.1 \%$ ). Instead, choanoflagellate silicon isotopic fractionation appears to be more similar to sponges grown under similar dissolved silica concentrations. Our results highlight that there is a taxonomic component to silicon isotope fractionation during biosilicification, possibly via a shared or related biochemical transport pathway. These findings have implications for the use of biogenic silica $\delta^{30} \mathrm{Si}$ produced by different silicifiers as proxies for past oceanic change.
\end{abstract}

\section{Introduction}

The global silicon cycle is coupled directly to the carbon cycle in part because silica is used in the biology of various organisms. A prime example of this occurs in the case of the diatoms, siliceous algae that play a key role in the cycling of organic matter in oceans, being responsible for approximately half of the export of organic carbon from surface waters to the deep (Tréguer et al., 2018). For most (although not all) diatoms, dissolved silica (DSi) is an essential nutrient since it is required for the formation of silicified cell walls, known as frustules (Darley and Volcani, 1969; Hildebrand, 2008; Sapriel et al., 2009). Because of this direct link between biosilicification and primary production, quantifying the supply and uptake of DSi through time is important for understanding historical changes in the marine carbon cycle arising from fluctuations in climate (Tréguer and De La Rocha, 2013). This is determined by studying the stable silicon isotopic composition $\left(\delta^{30} \mathrm{Si}\right)$ of biogenic silica within marine sediments, which act as a geochemical archive of the silicon cycle (Sutton et al., 2018).

It is now clear that silicon isotopes are fractionated during biosilicification and that this phenomenon provides important information on past DSi concentrations in seawater. For example, diatom frustules are enriched in the lighter isotope, ${ }^{28} \mathrm{Si}$, relative to the heavier isotopes, ${ }^{29} \mathrm{Si}$ and ${ }^{30} \mathrm{Si}$ (De La Rocha et al., 1997). During periods of intense productivity, this makes the Si isotopic composition of the ambient seawater increasingly heavy; in turn, this altered environment drives the newly formed biogenic silica towards 
heavier isotopic compositions. By making assumptions about the composition of seawater and the fractionation factor $(\varepsilon)$, it is possible to calculate past surface DSi utilisation (and so, diatom productivity) from the isotopic composition of the frustule. The value of $\varepsilon$ for the diatoms is generally taken as $-1.1 \%$, and this assumption appears to be robust across different regimes of temperature, $\mathrm{pH}$, and nutrients from a range of culture, mesocosm, and field experiments (De La Rocha et al., 1997; Milligan et al., 2004; Varela et al., 2004; Beucher et al., 2008; Egan et al., 2012; Sun et al., 2014; Meyerink et al., 2019). However, culture experiments have highlighted that diatoms may exhibit some species-dependent differences in isotopic behaviour (Sutton et al., 2013). In contrast, apparent fractionation in benthic sponge spicules shows considerable variability, with an empirical non-linear relationship with ambient DSi concentrations (Hendry et al., 2010; Wille et al., 2010). These data are derived from geochemical approaches that have been applied in a range of palaeoceanographic settings, and we do not yet have a full understanding of the mechanism or the biochemical pathway(s) responsible for $\mathrm{Si}$ isotopic fractionation (Hendry et al., 2019). A fuller understanding of this phenomenon will require systematic comparative studies across diverse silicifiers.

There are several phases during biosilicification where isotopic fractionation could occur. It has been helpful to conceive this complex process as three interrelated stages: (i) DSi influx across the plasmalemma into the cytoplasm, followed by accumulation in a cellular compartment known as the silica deposition vesicle (SDV), (ii) net incorporation of $\mathrm{Si}$ via polymerisation within this cellular compartment, and (iii) regulatory efflux of excess DSi from the cell. Laboratory culture experiments indicate that DSi influx, rather than polymerisation or efflux, is probably the key step in determining $\varepsilon$ in diatoms (Milligan et al., 2004). In contrast, biological models based on Michaelis-Menten kinetics and empirical data from growth rate experiments suggest that the largest contribution towards isotopic fractionation in sponges occurs during the polymerisation step rather than during influx or efflux of DSi. Fractionation values are estimated as approximately $-1.5 \%$ and $-5.3 \%$ for influx and net polymerisation efflux, respectively, during sponge biomineralisation (Hendry and Robinson, 2012; Wille et al., 2010). However, there are considerable uncertainties with both laboratory and model-based approaches, the latter of which are based largely on empirical observations as opposed to a mechanistic understanding.

Given that there are currently no estimates of Si isotopic fractionation from culture or water column studies of other silicifiers, placing isotopic fractionation in a phylogenetic framework is not possible at present. A wide diversity of species biomineralise silica to some extent, with siliceous organisms being found right across the various eukaryotic supergroups (Marron et al., 2016; Hendry et al., 2018) despite these groups diverging over $2.1 \mathrm{Ga}$ (Parfrey et al., 2011). The evolutionary history of eukaryotic biosilicification is largely opaque; though there is good evidence for the independent evolution of biosilicification in some taxa (Grégoire et al., 2012; Shimizu et al., 2015; Marron et al., 2016; Ratcliffe et al., 2017), there is support for a common origin, deep in the eukaryotic phylogeny, of several of the genes and biochemical mechanisms involved in silicon transport and polymerisation (e.g. the role of long-chain polyamines Sumper and Kröger, 2004; Matsunaga et al., 2007; Durak et al., 2016). Understanding the links between evolutionary relationships and silicon isotope fractionation could provide insight into the mechanisms underpinning biosilicification and isotopic fractionation. Furthermore, evidence from other elemental proxies (e.g. $\left.\delta^{13} \mathrm{C}\right)$ suggests that there are phylogenetically specific effects on their isotopic fractionation (Edgar et al., 2017), and it is therefore important to discover if such biases need to be corrected for when using measurements of silicon isotopes.

Here, we present the first measurements of silicon isotopic fractionation in laboratory cultures of choanoflagellates. Choanoflagellates are aquatic (marine and freshwater) unicellular or colonial eukaryotes typically $<10 \mu \mathrm{m}$ in size, characterised by a single apical flagellum surrounded at its base by a collar of microvilli (Nitsche, 2014; Paul, 2012; Richter and Nitsche, 2016). Choanoflagellates are the closest living sister group to animals (King et al., 2008; RuizTrillo et al., 2008; Nitsche et al., 2011) and possess cytological features often observed as being similar to sponge collar cells (Mah et al., 2014). This is noteworthy as sponges are believed to represent the most basal, or at the very least an early diverging, clade within the animal kingdom (Simion et al., 2017). However, there is no known microfossil record for choanoflagellates (Leadbeater, 2015). One family of choanoflagellates, the Acanthoecidae, produce an extracellular lorica composed of multiple silicified costal strips. The siliceous costal strips are formed inside the cell before being exocytosed to the cell exterior (Leadbeater, 2015). Molecular studies suggest that this process is mediated by biochemical pathways that are broadly comparable to other silicifiers; for example, the presence of silicon transporter (SIT) genes (Hildebrand et al., 1997; Durak et al., 2016; Marron et al., 2016), the role of the cytoskeleton in shaping the forming costal strip (Froesler and Leadbeater, 2009; Tesson and Hildebrand, 2010; Nomura and Ishida, 2016; Durak et al., 2017), and the involvement of glycoproteins in biosilica polymerisation (Ludwig et al., 1996; Gong et al., 2010). Understanding Si isotopic fractionation in choanoflagellates therefore has implications for the evolution of biosilicification pathways in animals and across eukaryotes and for the use of Si isotopic archives as environmental proxies.

\section{Material and methods}

Silicon isotope variations are denoted throughout by $\delta^{30} \mathrm{Si}$, reported relative to a known standard (NIST quartz standard 
NBS28 RM8546) according to Eq. (1):

$\delta^{30} \mathrm{Si}(\% o)=\left(\frac{\left(\frac{30 \mathrm{Si}}{{ }^{28} \mathrm{Si}}\right)_{\text {Sample }}}{\left(\frac{30 \mathrm{Si}}{{ }^{28} \mathrm{Si}}\right)_{\mathrm{NBS} 28}}-1\right) \times 1000$.

Two species of marine choanoflagellates, Diaphanoeca grandis and Stephanoeca diplocostata (Family Acanthoecidae, Nitsche et al., 2011) were cultured in artificial seawater (ASW) made from $36.5 \mathrm{~g} \mathrm{~L}^{-1}$ of a single batch of Marin salts (Dr. Biener Aquarientechnik, Wartenberg Germany) in double-distilled (dd) $\mathrm{H}_{2} \mathrm{O}$. ASW was vacuumfiltered through a $0.22 \mu \mathrm{m}$ Steriop GP Express Plus filter (Millipore, MA) into a sterile $1 \mathrm{~L}$ screw-top glass bottle (Schott Duran) and sterilised by autoclaving. Organic enrichment medium $\left(4 \mathrm{~g} \mathrm{~L}^{-1}\right.$ proteose peptone from Sigma and $0.8 \mathrm{~g} \mathrm{~L}^{-1}$ yeast extract from Fluka Biochemika in ddHO, autoclaved sterile material) was added to new cultures at a concentration of $7.5 \mu \mathrm{L} \mathrm{mL}^{-1}$ ASW to provide nutrition for prey bacteria. Cultures of both species were grown in $50 \mathrm{~mL}$ polystyrene triangular flasks (Corning) at $13.5^{\circ} \mathrm{C}$ and split every 4 to 8 weeks. Several litres of culture were required to obtain sufficient siliceous material for analysis. Cultures were growing in the culture medium for a minimum of 2 months (for Diaphanoeca grandis) and 7 months (for Stephanoeca diplocostata) before harvesting. It should be noted that there is no evidence that loricate choanoflagellates store reserves of silicon or DSi (Leadbeater, 1987, 1989; Leadbeater and Cheng, 2010).

Cells were harvested by centrifugation at $4000 \mathrm{~g}$ for $60 \mathrm{~min}$ at $4{ }^{\circ} \mathrm{C}$. The pellet was washed in $10 \mathrm{~mL} \mathrm{ddH}_{2} \mathrm{O}$, resuspended by vortexing, sonicated for $5 \mathrm{~min}$, and centrifuged again at $4000 \mathrm{~g}$ for $90 \mathrm{~min}$ at $4{ }^{\circ} \mathrm{C}$. The washed pellet was oven-dried overnight at $50^{\circ} \mathrm{C}$.

Organic matter was removed from the pelleted loricae by heating in $30 \%$ hydrogen peroxide at $80^{\circ} \mathrm{C}$ for an hour. The cleaned loricae were washed once in $18 \mathrm{M} \Omega \mathrm{cm}$ deionised water, resuspended in a small amount of water in a clean Teflon vial and dried under vacuum. This pellet was resuspended in $100 \mu \mathrm{L}$ of distilled concentrated nitric acid and dried again. The silica from the loricae was solubilised in $1 \mathrm{~mL}$ of $0.4 \mathrm{M}$ sodium hydroxide solution (Titrapur) at $100^{\circ} \mathrm{C}$ overnight. The resulting solution was acidified with $50 \mu \mathrm{L}$ of in-house distilled $8 \mathrm{M}$ nitric acid and diluted with $1 \mathrm{~mL}$ of water before the dissolved silica was purified by cation exchange chromatography (Georg et al., 2006; Hendry et al., 2019).

Full biological triplicates were available for $S$. diplocostata; material from only one sample of pelleted loricae was available for $D$. grandis, but this was split into three aliquots to make analytical triplicates. Samples of the growth medium used in the cultures were analysed in duplicate for DSi and isotopic composition. The DSi concentrations of the fresh medium, post-culture medium (D. grandis only), and organic enrichment medium were measured using a molyb- date blue spectrophotometric method (Hach Lange), with an estimated precision of $3 \%$ based on replicate measurements of a $\mathrm{SiO}_{2}$ standard ( $<0.1 \%$ alkali fluorosilicate). The artificial seawater medium was prepared in duplicate for isotopic analysis using a magnesium co-precipitation method (Cassarino et al., 2018): $\mathrm{Si}$ was pre-concentrated by the addition of $1.2 \% v / v 1 \mathrm{M}$ sodium hydroxide $(\mathrm{NaOH})$, followed by $1 \% v / v 1 \mathrm{M} \mathrm{NaOH}$ after $24 \mathrm{~h}$. The precipitate was rinsed with $1 \mathrm{mM} \mathrm{NaOH}$ before dissolution in in-house distilled $6 \mathrm{~N}$ $\mathrm{HCl}$, dilution in Milli-Q water, and purification using cation exchange resins.

Silicon isotopes were measured using Multi-Collector Inductively Coupled Plasma Mass Spectrometry (MC-ICP-MS Thermo Neptune, Bristol Isotope Group). Mass bias corrections were carried out offline using both standard-sample bracketing with standard NBS28 (RM8546) and magnesium isotope doping (Cardinal et al., 2003). All standards and samples were doped with a magnesium solution, intensity matched with ${ }^{28} \mathrm{Si}$. Seawater samples (and associated bracketing standards) were additionally doped with $0.05 \mathrm{M} \mathrm{HCl}$ and $0.003 \mathrm{M} \mathrm{H}_{2} \mathrm{SO}_{4}$ to account for matrix effects (Hughes et al., 2011).

Sample ${ }^{29} \mathrm{Si}$ and ${ }^{30} \mathrm{Si}$ values were related linearly, with a gradient of 0.522 (SE 0.007, $R^{2}>0.99$ ), which is within the range of theoretical mass-dependent fractionation. Rock reference standard Diatomite (Reynolds et al., 2007) and sponge standard LMG08 (Hendry et al., 2011) are used to assess long-term reproducibility, yielding $\delta^{30} \mathrm{Si}$ values of $+1.23 \pm 0.15 \%$ and $-3.44 \pm 0.16 \%$ ( $2 \mathrm{SD}$ ), respectively (Cassarino et al., 2018). As an additional quality check, the new seawater standard ALOHA deep was analysed and give a $\delta^{30} \mathrm{Si}$ values of $+1.11 \pm 0.18 \%$ ( $2 \mathrm{SD}$ ). All standards fell well within error of published values (Grasse et al., 2017).

\section{Results}

\subsection{DSi concentrations in growth media}

For cultures of $D$. grandis we determined that ASW culture media had DSi concentrations of 94 and $89 \mu \mathrm{M}$, respectively. Measuring the same media after culturing determined that $94 \%( \pm 4 \%)$ of the available Si remained in solution after the choanoflagellate growth. The concentrated organic enrichment medium contained $44 \mu \mathrm{M}$ DSi but was only added to a working concentration of $0.75 \%(v / v)$. The change in $\mathrm{Si}$ isotopic composition of the ASW from the organic enrichment medium is thus considered negligible.

\subsection{Isotopic compositions of choanoflagellates and growth media}

The $\delta^{30} \mathrm{Si}$ composition of ASW growth medium was $+3.33 \pm$ $0.05 \%$. The $\delta^{30} \mathrm{Si}$ composition of choanoflagellate loricate silica was $-3.32 \pm 0.07 \%$ of $D$. grandis (analytical triplicates, $1 \mathrm{SE}$ ) and $-2.38 \pm 0.07 \%$ for $S$. diplocostata (biolog- 


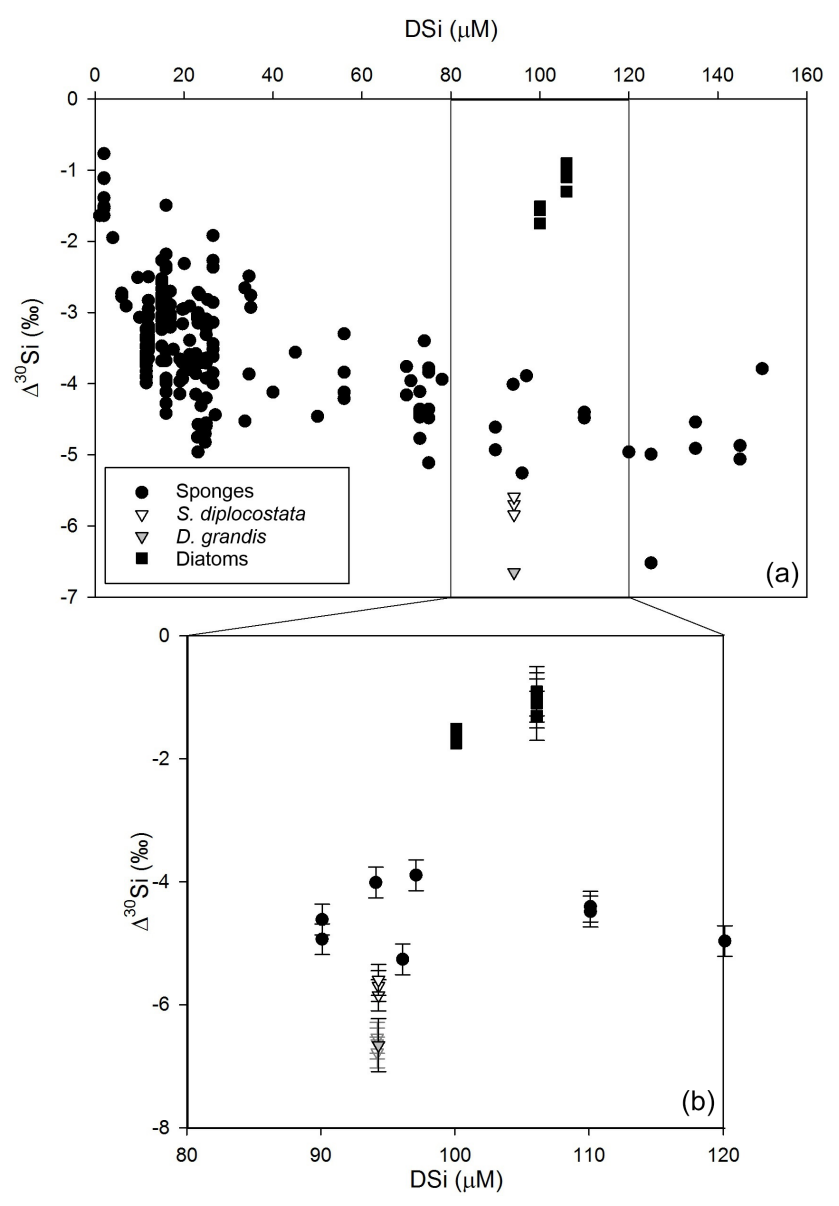

Figure 1. Apparent fractionation $\left(\Delta^{30} \mathrm{Si}\right.$, Eq. 2) of choanoflagellates (this study, triangles), sponges (circles, Hendry et al., 2010; Wille et al., 2010; Hendry and Robinson, 2012; Cassarino et al., 2018), and fractionation ( $\varepsilon$, Eq. 4) from diatom cultures (squares, De La Rocha et al., 1997; Milligan et al., 2004). Note that for the diatoms, the only available comparative data come from a narrow concentration range at approximately $100 \mu \mathrm{M}$ DSi. Panel (b) expands the values for all organisms grown in DSi concentrations of $80-120 \mu \mathrm{M}$. The error bars show 2 SD errors based on replicate measurements of biogenic silica standards (see the main text). For D. grandis, the analytical replicates are shown in hollow grey triangles, mean ( $\pm 2 \mathrm{SD}$ of the replicates) is shown in the solid grey triangle.

ical triplicates, $1 \mathrm{SE}$; Table 1). Given that the overall drawdown of DSi was so low, the fractionation factor, $\varepsilon$, was assumed to approximate the apparent fractionation $\Delta^{30} \mathrm{Si}$ calculated using Eq. (2) (Fig. 1):

$\varepsilon \approx \Delta^{30} \mathrm{Si}=\delta^{30} \mathrm{Si}_{\text {choano }}-\delta^{30} \mathrm{Si}_{\mathrm{ASW}}$.

Figure 1 compares $\Delta^{30} \mathrm{Si}$ from the current study to previous literature values for other marine silicifiers.

The impact of DSi utilisation on calculation of $\varepsilon$ can be assessed for the D. grandis culture, given that the DSi concentration of the media was measured before and after cell
Table 1. Silicon isotopic composition of choanoflagellates and growth media. Numbers in parentheses show 1 SD internal errors; \pm shows external error from biological triplicates.

\begin{tabular}{lrr}
\hline $\begin{array}{l}\text { S. diplocostata } \\
\delta^{30} \mathrm{Si}(\% \circ)\end{array}$ & $\begin{array}{r}\text { D. grandis } \\
\delta^{30} \mathrm{Si}(\% \circ)\end{array}$ & $\begin{array}{r}\text { Growth medium } \\
\delta^{30} \mathrm{Si}(\% \circ)\end{array}$ \\
\hline$-2.36(0.08)$ & $-3.32 \pm 0.07$ & $3.28(0.15)$ \\
$-2.51(0.07)$ & & $3.38(0.12)$ \\
$-2.26(0.11)$ & & \\
\hline
\end{tabular}

growth. Assuming a closed system, $\varepsilon$ can be calculated according to Eq. (3):

$\varepsilon \approx 1000(\alpha-1)$,

where $\alpha$ is defined by Eq. (4) (Sutton et al., 2013).

$\alpha=\frac{\ln \left(1-\frac{\left(1+\delta^{30} \operatorname{Si}_{\text {choano }} / 1000\right)(1-f)}{1+\delta^{30} \mathrm{Si}_{\mathrm{ASW}} / 1000}\right)}{\operatorname{In}(f)}$

Here $f$ is the fraction of DSi remaining in solution. This calculation suggests that a $6 \%$ utilisation may increase the calculated fractionation by approximately $0.2 \%$, which is the same as a conservative estimate of uncertainty (1 SD).

\section{Discussion}

\subsection{Interspecies differences in choanoflagellate silicon isotopic fractionation}

There is a significant $1 \%$ offset between the two species of choanoflagellate. Whilst further work is required to understand the offset between the species, we can speculate on potential origins of this offset. Firstly, the difference may be a result of differences in growth rates between the two species (Andersen, 1988; Geider and Leadbeater, 1988; EcclestonParry and Leadbeater, 1994). However, the observed growth rates were highly variable and did not show systematic differences between the two species. Secondly, the difference in fractionation could be due to the difference in the degree of silicification between the two species, with Stephanoeca lorica being composed of a greater number of silicified costal strips than Diaphanoeca lorica.

\subsection{Implications for evolution of silicon isotopic fractionation by biosilicifiers}

We show here that two silicifying choanoflagellate species both exhibit $\mathrm{Si}$ fractionation that is more similar to sponges and markedly different from diatoms grown under equivalent culture conditions. This is consistent with the phylogenetic relationships of these organisms, with choanoflagellates being more closely related phylogenetically to the sponges than 
either of these are to the diatoms (Adl et al., 2019). These results have implications for the mechanistic basis of fractionation. One possibility is that silicon isotopic fractionation occurs at the precipitation stage. This could explain the differences observed between sponges and diatoms, which use different biomolecules to drive silica formation. Though some features of silicification are shared between sponges and diatoms, e.g. long-chain polyamines, (Sumper and Kröger, 2004; Matsunaga et al., 2007), sponges lack many of the molecules that are key features of diatom biosilica formation, such as silaffins (Kroger et al., 2002) and silacidins (Wenzl et al., 2008). However, our results argue against silica precipitation being a key driver for isotopic fractionation. Sponge silica spicules are deposited around a core protein filament (e.g. silicatein, glassin), and such proteins are apparently absent from analyses of choanoflagellate costal strip proteins or transcriptomes (Gong et al., 2010; Richter et al., 2018). Without molecular evidence for common biosilica formation pathways, it is difficult to envisage how comparable values could occur between sponges and choanoflagellates if specific mineral-forming mechanisms were responsible for fractionation. To place this observation in a broader context, different sponges can use very different proteins during silicification, yet have consistent isotopic fractionation across clades (Hendry et al., 2019). Although we cannot rule out that the different polymerisation pathways all fortuitously give rise to the same degree of fractionation, this seems unlikely.

Another possibility is that fractionation occurs during silica uptake into the cell. Available evidence indicates that the cellular influx of DSi is generally governed by active or passive membrane transport proteins under physiological conditions (Maldonado et al., 2011; Marron et al., 2016; Thamatrakoln and Hildebrand, 2007; Thamatrakoln and Kustka, 2009). Candidates for mediating this active transport include the SITs and related SIT-L transporter proteins, which occur in a wide variety of silicifiers, such as diatoms, haptophytes, radiolarians, and choanoflagellates. A separate group of active transporters known as the Lsi2-like family were first identified in plants (Ma and Yamaji, 2015) and have now been found throughout the eukaryotes (see Fig. 2), including sponges, as well as in archeans and eubacteria (Marron et al., 2016). Examples of passive transporters are modified aquaporins like the plant Lsi1s (Ma and Yamaji, 2015), which have specialised channel pore sizes and selectivity filters that make them permeable to DSi (Mitani-Ueno et al., 2011).

Diatoms and choanoflagellates both possess SIT genes, whereas sponges do not. This implies that if the SITs were solely responsible for silicon isotopic fractionation then values for choanoflagellates and diatoms should be similar, and distinct from the sponges. Our data argue against this, showing instead that choanoflagellate fractionation is much closer to the sponges under the conditions tested. We speculate that if fractionation does occur during influx and assimilation, it could be mediated instead by Lsi2-type

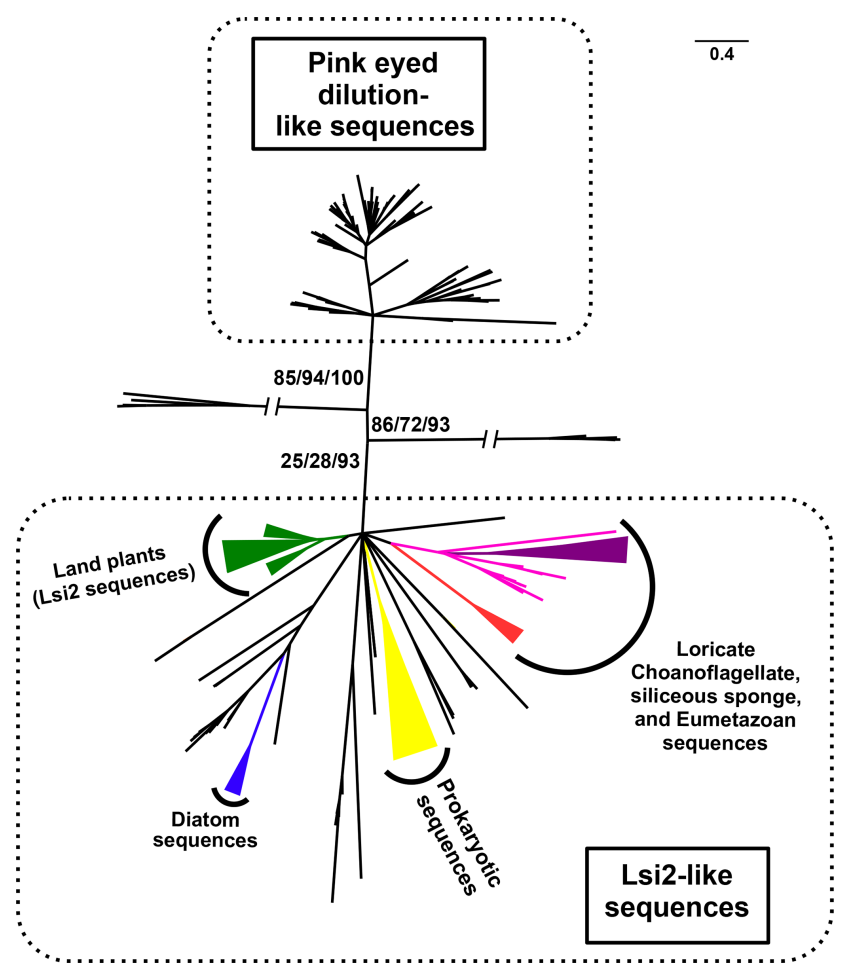

Figure 2. Simplified phylogenetic tree of Lsi2-like sequences (adapted from Marron et al., 2016). Phylogenetic tree of sequence similar to the rice active $\mathrm{Si}$ transporter low silicon 2 (Lsi2) from a taxonomically diverse range of eukaryotes and prokaryotes. The sequences divide into two main groups: one containing pink-eyed dilution P-protein sequences and the other containing the plant Lsi2s, hence being designated as Lsi2-like. Among the opisthokonts investigated, only loricate choanoflagellates (red); siliceous sponges (magenta); and the biosilica-producing eumetazoans Lottia gigantea, Capitella teleta, and Lingula anatina (purple) possessed Lsi2like sequences. The opisthokont sequences clearly branch in a manner distinct from the diatom sequences (in blue). The support for the eumetazoan clade is $97 / 97 / 99$, for the sponge + eumetazoan clade it is $93 / 99 / 100$, and for the loricate choanoflagellate + siliceous sponge + eumetazoan branch it is $31 / 36 / 89$. Plant Lsi2 sequences (green) form a strongly supported (86/99/100) monophyletic clade, as do the diatom Lsi2-like sequences (100/100/100) and prokaryotic arsB (yellow) sequences (74/90/98). This tree was produced using RaxML maximum likelihood analysis with the best-fitting LG + G4 model from an alignment of 247 amino acid residues, analyses were also conducted with PhyML and IQ-Tree under the same model. Statistical support values are given in the form $\%$ RaxML/\%PhyML/\%IQ-Tree bootstrap. Nodes with $<20 \%$ bootstrap support were collapsed to give a topology agreed across all methods. The scale bar indicates the average number of amino acid substitutions per site; slashes indicate very long branches that were clipped for display purposes.

transporters. While sponges, diatoms and choanoflagellates all contain Lsi2-like proteins, the sponge and choanoflagellate genes are more closely related to each other than to the diatom sequences (Fig. 2; see also Marron et al., 
2016). Lsi2 genes are also responsible for silicon transport in plants, and studies have implicated them in isotopic fractionation (Opfergelt et al., 2006). Within the Lsi2-like phylogeny, the land plant Lsi2 clade is distinct from the "sponge + choanoflagellate + eumetazoan" Lsi2-branch and from the diatom sequences (Marron et al., 2016). This is in line with the much lower fractionation values observed for plant biosilica, with the caveat that the siliceous plants studied were grown under different conditions (reviewed in Frings et al., 2016).

Finally, it is also plausible that fractionation is influenced by silica efflux from the cell. However, the molecular basis for this process remains so ill-defined that it is difficult to draw conclusions on this from the data presented here.

\section{Conclusions and outlook}

Choanoflagellates grown in culture exhibit strong silicon isotopic fractionation during biosilicification, comparable to that of sponges grown under equivalent DSi concentrations in natural conditions. This similarity between choanoflagellates and sponges indicates that the biochemical pathway responsible for the fractionation of silicon isotopes is shared between the two sister taxa. We postulate that influx of DSi by Lsi2-type transporters play a key role but that further testing with other silicifiers for inter- and intra-clade comparisons will provide further insight into this pathway.

The hypothesis that the fractionation of silicon isotopes during biosilicification has its basis in phylogeny will influence how we view the use of silicon isotope-based oceanic archives, as a better mechanistic understanding of such proxies allows more robust interpretation of downcore records. Furthermore, this phylogenetic framework has implications for the long-term history of silicon and silicon isotope budgets in the biosphere (Tatzel et al., 2017). Whole ocean DSi concentrations are likely to have been coupled over geological timescales with the evolution of silicifiers even before the emergence of the diatoms (Conley et al., 2017; Hendry et al., 2018). If strong silicon isotopic fractionation is indeed driven largely by cellular transporters, the origin of which extends back into the Precambrian, then such coupling would also have impacted the isotopic composition of the oceans at least as far back as a billion years ago.

Data availability. The new data used for this paper are shown in Table 1.

Author contributions. AM, PC, and KRH devised the study, wrote the majority of the text, and produced the figures. AM carried out the cultures. $\mathrm{KRH}, \mathrm{LC}$, and $\mathrm{JH}$ conducted the isotopic analysis.
Competing interests. The authors declare that they have no conflict of interest.

Acknowledgements. The authors would like to thank Christopher D. Coath for assistance with mass spectrometry. Katharine R. Hendry is funded by the Royal Society and the European Research Council. Alan O. Marron was funded by the European Research Council and a Wellcome Trust Senior Investigator Award to Raymond E. Goldstein. Many thanks to Patricia Grasse and an anonymous reviewer for constructive comments.

Financial support. This research has been supported by the Royal Society (grant no. RG130386) and the European Research Council: ICY-LAB (grant no. 678371) and BIOCOMPLEX (grant no. 247333)

Review statement. This paper was edited by Aldo Shemesh and reviewed by Patricia Grasse and one anonymous referee.

\section{References}

Adl, S. M., Bass, D., Lane, C. E., Lukes, J., Schoch, C. L., Smirnov, A., Agatha, S., Berney, C., Brown, M. W., Burki, F., Cardenas, P., Cepicka, I., Chistyakova, L., del Campo, J., Dunthorn, M., Edvardsen, B., Eglit, Y., Guillou, L., Hampl, V., Heiss, A. A., Hoppenrath, M., James, T. Y., Karnkowska, A., Karpov, S., Kim, E., Kolisko, M., Kudryavtsev, A., Lahr, D. J. G., Lara, E., Le Gall, L., Lynn, D. H., Mann, D. G., Massana, R., Mitchell, E. A. D., Morrow, C., Park, J. S., Pawlowski, J. W., Powell, M. J., Richter, D. J., Rueckert, S., Shadwick, L., Shimano, S., Spiegel, F. W., Torruella, G., Youssef, N., Zlatogursky, V., and Zhang, Q.: Revisions to the Classification, Nomenclature, and Diversity of Eukaryotes, J. Eukaryot. Microbiol., 66, 4-119, https://doi.org/10.1111/jeu.12691, 2019.

Andersen, P.: Functional biology of the choanoflagellate Diaphanoeca grandis Ellis, Marine Microbial Food Webs, 3, 35-49, 1988.

Beucher, C. P., Brzezinski, M. A., and Jones, J. L.: Sources and biological fractionation of Silicon isotopes in the Eastern Equatorial Pacific, Geochim. Cosmochim. Ac., 72, 3063-3073, 2008.

Cardinal, D., Alleman, L. Y., de Jong, J., Ziegler, K., and André, L.: Isotopic composition of silicon measured by multicollector plasma source mass spectrometry in dry plasma mode, J. Anal Atom. Spectrom., 18, 213-218, 2003.

Cassarino, L., Coath, C. D., Xavier, J. R., and Hendry, K. R.: Silicon isotopes of deep sea sponges: new insights into biomineralisation and skeletal structure, Biogeosciences, 15, 6959-6977, https://doi.org/10.5194/bg-15-6959-2018, 2018.

Conley, D. J., Frings, P. J., Fontorbe, G., Clymans, W., Stadmark, J., Hendry, K. R., Marron, A. O., and De La Rocha, C. L.: Biosilicification Drives a Decline of Dissolved Si in the Oceans through Geologic Time, Frontiers in Marine Science, 4, https://doi.org/10.3389/fmars.2017.00397, 2017.

Darley, W. M. and Volcani, B.: Role of silicon in diatom metabolism: a silicon requirement for deoxyribonucleic acid 
synthesis in the diatom Cylindrotheca fusiformis Reimann and Lewin, Exp. Cell Res., 58, 334-342, 1969.

De La Rocha, C. L., Brzezinski, M. A., and DeNiro, M. J.: Fractionation of silicon isotopes by marine diatoms during biogenic silica formation, Geochim. Cosmochim. Ac., 61, 5051-5056, 1997.

Durak, G. M., Taylor, A. R., Walker, C. E., Probert, I., De Vargas, C., Audic, S., Schroeder, D., Brownlee, C., and Wheeler, G. L.: A role for diatom-like silicon transporters in calcifying coccolithophores, Nat. Commun., 7, 10543, https://doi.org/10.1038/ncomms 10543, 2016.

Durak, G. M., Brownlee, C., and Wheeler, G. L.: The role of the cytoskeleton in biomineralisation in haptophyte algae, Sci. Rep.-UK, 7, 15409, https://doi.org/10.1038/s41598-017-155628, 2017.

Eccleston-Parry, J. D. and Leadbeater, B. S.: A comparison of the growth kinetics of six marine heterotrophic nanoflagellates fed with one bacterial species, Mar. Ecol.-Prog. Ser., 105, 167-177, 1994.

Edgar, K. M., Hull, P. M., and Ezard, T. H.: Evolutionary history biases inferences of ecology and environment from $\delta^{13} \mathrm{C}$ but not $\delta^{18} \mathrm{O}$ values, Nat. Commun., 8, 1106, https://doi.org/10.1038/s41467-017-01154-7, 2017.

Egan, K. E., Rickaby, R. E., Leng, M. J., Hendry, K. R., Hermoso, M., Sloane, H. J., Bostock, H., and Halliday, A. N.: Diatom silicon isotopes as a proxy for silicic acid utilisation: a Southern Ocean core top calibration, Geochim. Cosmochim. Ac., 96, 174192, 2012.

Frings, P. J., Clymans, W., Fontorbe, G., De La Rocha, C. L., and Conley, D. J.: The continental Si cycle and its impact on the ocean $\mathrm{Si}$ isotope budget, Chem. Geol., 425, 12-36, https://doi.org/10.1016/j.chemgeo.2016.01.020, 2016.

Froesler, J. and Leadbeater, B. S.: Role of the cytoskeleton in choanoflagellate lorica assembly, J. Eukaryot. Microbiol., 56, 167-173, 2009.

Geider, R. J. and Leadbeater, B. S.: Kinetics and energetics of growth of the marine choanoflagellate Stephanoeca diplocostata, Mar. Ecol.-Prog. Ser., 47, 169-177, 1988.

Georg, R. B., Reynolds, B. C., Frank, M., and Halliday, A. N.: New sample preparation techniques for the determination of $\mathrm{Si}$ isotopic compositions using MC-ICPMS, Chem. Geol., 235, 95104, https://doi.org/10.1016/j.chemgeo.2006.06.006, 2006.

Gong, N., Wiens, M., Schröder, H. C., Mugnaioli, E., Kolb, U., and Müller, W. E.: Biosilicification of loricate choanoflagellate: organic composition of the nanotubular siliceous costal strips of Stephanoeca diplocostata, J. Exp. Biol., 213, 3575-3585, 2010.

Grasse, P., Brzezinski, M. A., Cardinal, D., de Souza, G. F., Andersson, P., Closset, I., Cao, Z., Dai, M., Ehlert, C., Estrade, N., Francois, R., Frank, M., Jiang, G., Jones, J. L., Kooijman, E., Liu, Q., Lu, D., Pahnke, K., Ponzevera, E., Schmitt, M., Sun, X., Sutton, J. N., Thil, F., Weis, D., Wetzel, F., Zhang, A., Zhang, J., and Zhang, Z.: GEOTRACES inter-calibration of the stable silicon isotope composition of dissolved silicic acid in seawater, J. Anal. Atom. Spectrom., 32, 562-578, https://doi.org/10.1039/c6ja00302h, 2017.

Grégoire, C., Rémus-Borel, W., Vivancos, J., Labbé, C., Belzile, F., and Bélanger, R. R.: Discovery of a multigene family of aquaporin silicon transporters in the primitive plant Equisetum arvense, Plant J., 72, 320-330, 2012.
Hendry, K. R. and Robinson, L. F.: The relationship between silicon isotope fractionation in sponges and silicic acid concentration: Modern and core-top studies of biogenic opal, Geochim. Cosmochim. Ac., 81, 1-12, 2012.

Hendry, K. R., Georg, R. B., Rickaby, R. E., Robinson, L. F., and Halliday, A. N.: Deep ocean nutrients during the Last Glacial Maximum deduced from sponge silicon isotopic compositions, Earth Planet. Sc. Lett., 292, 290-300, 2010.

Hendry, K. R., Leng, M. J., Robinson, L. F., Sloane, H. J., Blusztjan, J., Rickaby, R. E., Georg, R. B., and Halliday, A. N.: Silicon isotopes in Antarctic sponges: an interlaboratory comparison, Antarct. Sci., 23, 34-42, 2011.

Hendry, K. R., Marron, A. O., Vincent, F., Conley, D. J., Gehlen, M., Ibarbalz, F. M., Quéguiner, B., and Bowler, C.: Competition between silicifiers and non-silicifiers in the past and present ocean and its evolutionary impacts, Front. Mar. Sci., 5, 22, https://doi.org/10.3389/fmars.2018.00022, 2018.

Hendry, K. R., Cassarino, L., Bates, S. L., Culwick, T., Frost, M., Goodwin, C., and Howell, K. L.: Silicon isotopic systematics of deep-sea sponge grounds in the North Atlantic, Quaternary Sci Rev., 210, 1-14, 2019.

Hildebrand, M.: Diatoms, biomineralization processes, and genomics, Chem. Rev., 108, 4855-4874, 2008.

Hildebrand, M., Volcani, B. E., Gassmann, W., and Schroeder, J. I.: A gene family of silicon transporters, Nature, 385, 688-689, 1997.

Hughes, H. J., Delvigne, C., Korntheuer, M., de Jong, J., Andre, L., and Cardinal, D.: Controlling the mass bias introduced by anionic and organic matrices in silicon isotopic measurements by MC-ICP-MS, J. Anal. Atom. Spectrom., 26, 1892-1896, https://doi.org/10.1039/c1ja10110b, 2011.

King, N., Westbrook, M. J., Young, S. L., Kuo, A., Abedin, M., Chapman, J., Fairclough, S., Hellsten, U., Isogai, Y., Letunic, I., and Marr, M.: The genome of the choanoflagellate Monosiga brevicollis and the origin of metazoans, Nature, 451, 783, 2008.

Kroger, N., Lorenz, S., Brunner, E., and Sumper, M.: Selfassembly of highly phosphorylated silaffins and their function in biosilica morphogenesis, Science, 298, 584-586, https://doi.org/10.1126/science.1076221, 2002.

Leadbeater, B.: Developmental studies on the loricate choanoflagellateStephanoeca diplocostata Ellis. V. The cytoskeleton and the effects of microtubule poisons, Protoplasma, 136, 1-15, 1987.

Leadbeater, B.: Developmental studies on the loricate choanoflagellateStephanoeca diplocostata Ellis VI. Effects of silica replenishment on silica impoverished cells, Protoplasma, 153, 71-84, 1989.

Leadbeater, B. S.: The Choanoflagellates, Cambridge University Press, Cambridge, 2015.

Leadbeater, B. S. and Cheng, R.: Costal strip production and lorica assembly in the large tectiform choanoflagellate Diaphanoeca grandis Ellis, Eur. J. Protistol., 46, 96-110, 2010.

Ludwig, M., Lind, J. L., Miller, E. A., and Wetherbee, R.: High molecular mass glycoproteins associated with the siliceous scales and bristles of Mallomonas splendens (Synurophyceae) may be involved in cell surface development and maintenance, Planta, 199, 219-228, 1996.

Ma, J. F. and Yamaji, N.: A cooperative system of silicon transport in plants, Trends Plant Sci., 20, 435-442, https://doi.org/10.1016/j.tplants.2015.04.007, 2015. 
Mah, J. L., Christensen-Dalsgaard, K. K., and Leys, S. P.: Choanoflagellate and choanocyte collar-flagellar systems and the assumption of homology, Evol. Dev., 16, 25-37, 2014.

Maldonado, M., Navarro, L., Grasa, A., Gonzalez, A., and Vaquerizo, I.: Silicon uptake by sponges: a twist to understanding nutrient cycling on continental margins, Sci. Rep.-UK, 1, 30, https://doi.org/10.1038/srep00030, 2011.

Marron, A. O., Ratcliffe, S., Wheeler, G. L., Goldstein, R. E., King, N., Not, F., De Vargas, C., and Richter, D. J.: The evolution of silicon transport in eukaryotes, Mol. Biol. Evol., 33, 3226-3248, 2016.

Matsunaga, S., Sakai, R., Jimbo, M., and Kamiya, H.: Long-chain polyamines (LCPAs) from marine sponge: possible implication in spicule formation, ChemBioChem, 8, 1729-1735, 2007.

Meyerink, S. W., Boyd, P. W., Maher, W. A., Milne, A., Strzepek, R., and Ellwood, M. J.: Putting the silicon cycle in a bag: Field and mesocosm observations of silicon isotope fractionation in subtropical waters east of New Zealand, Mar. Chem., 213, 1-12, 2019.

Milligan, A. J., Varela, D. E., Brzezinski, M. A., and Morel, F. M.: Dynamics of silicon metabolism and silicon isotopic discrimination in a marine diatomas a function of $p \mathrm{CO}_{2}$, Limnol. Oceanogr., 49, 322-329, 2004.

Mitani-Ueno, N., Yamaji, N., Zhao, F.-J., and Ma, J. F.: The aromatic/arginine selectivity filter of NIP aquaporins plays a critical role in substrate selectivity for silicon, boron, and arsenic, J. Exp. Bot., 62, 4391-4398, https://doi.org/10.1093/jxb/err158, 2011.

Nitsche, F.: Stephanoeca arndti spec. nov. - First cultivation success including molecular and autecological data from a freshwater acanthoecid choanoflagellate from Samoa, Eur. J. Protistol., 50, 412-421, 2014.

Nitsche, F., Carr, M., Arndt, H., and Leadbeater, B. S.: Higher level taxonomy and molecular phylogenetics of the Choanoflagellatea, J. Eukaryot. Microbiol., 58, 452-462, 2011.

Nomura, M. and Ishida, K.-I.: Fine-structural observations on siliceous scale production and shell assembly in the testate amoeba Paulinella chromatophora, Protist, 167, 303-318, 2016.

Opfergelt, S., Cardinal, D., Henriet, C., Draye, X., Andre, L., and Delvaux, B.: Silicon isotopic fractionation by banana (Musa spp.) grown in a continuous nutrient flow device, Plant Soil, 285, 333-345, https://doi.org/10.1007/s11104-006-9019-1, 2006.

Parfrey, L. W., Lahr, D. J., Knoll, A. H., and Katz, L. A.: Estimating the timing of early eukaryotic diversification with multigene molecular clocks, P. Natl. Acad. Sci. USA, 108, 13624-13629, 2011.

Paul, M.: Acanthocorbis mongolica nov. spec.-Description of the first freshwater loricate choanoflagellate (Acanthoecida) from a Mongolian lake, Eur. J. Protistol., 48, 1-8, 2012.

Ratcliffe, S., Jugdaohsingh, R., Vivancos, J., Marron, A., Deshmukh, R., Ma, J. F., Mitani-Ueno, N., Robertson, J., Wills, J., Boekschoten, M. V., and Müller, M.: Identification of a mammalian silicon transporter, Am. J. Phys.-Cell Ph., 312, C550C561, 2017.

Reynolds, B. C., Aggarwal, J., Andre, L., Baxter, D., Beucher, C., Brzezinski, M. A., Engstrom, E., Georg, R. B., Land, M., Leng, M. J., Opfergelt, S., Rodushkin, I., Sloane, H. J., van den Boorn, S. H. J. M., Vroon, P. Z., and Cardinal, D.: An inter-laboratory comparison of $\mathrm{Si}$ isotope ref- erence materials, J. Anal. Atom. Spectrom., 22, 561-568, https://doi.org/10.1039/b616755a, 2007.

Richter, D. J. and Nitsche, F.: Choanoflagellatea, 1-19, Springer International Publishing, Cham, https://doi.org/10.1007/978-3319-32669-6_5-1, 2016.

Richter, D. J., Fozouni, P., Eisen, M. B., and King, N.: Gene family innovation, conservation and loss on the animal stem lineage, eLife, 7, e34226, https://doi.org/10.7554/eLife.34226, 2018.

Ruiz-Trillo, I., Roger, A. J., Burger, G., Gray, M. W., and Lang, B. F.: A phylogenomic investigation into the origin of metazoa, Mol. Biol. Evol., 25, 664-672, 2008.

Sapriel, G., Quinet, M., Heijde, M., Jourdren, L., Tanty, V., Luo, G., Le Crom, S., and Lopez, P. J.: Genome-wide transcriptome analyses of silicon metabolism in Phaeodactylum tricornutum reveal the multilevel regulation of silicic acid transporters, PloS one, 4, e7458, https://doi.org/10.1371/journal.pone.0007458, 2009.

Shimizu, K., Amano, T., Bari, M. R., Weaver, J. C., Arima, J., and Mori, N.: Glassin, a histidine-rich protein from the siliceous skeletal system of the marine sponge Euplectella, directs silica polycondensation, P. Natl. Acad. Sci. USA, 112, 11449-11454, 2015.

Simion, P., Philippe, H., Baurain, D., Jager, M., Richter, D. J., Di Franco, A., Roure, B., Satoh, N., Queinnec, E., Ereskovsky, A., and Lapebie, P.: A large and consistent phylogenomic dataset supports sponges as the sister group to all other animals, Curr. Biol., 27, 958-967, 2017.

Sumper, M. and Kröger, N.: Silica formation in diatoms: the function of long-chain polyamines and silaffins, J. Mater. Chem., 14, 2059-2065, 2004.

Sun, X., Olofsson, M., Andersson, P. S., Fry, B., Legrand, C., Humborg, C., and Mörth, C.-M.: Effects of growth and dissolution on the fractionation of silicon isotopes by estuarine diatoms, Geochim. Cosmochim. Ac., 130, 156-166, 2014.

Sutton, J. N., Varela, D. E., Brzezinski, M. A., and Beucher, C. P.: Species-dependent silicon isotope fractionation by marine diatoms, Geochim. Cosmochim. Ac., 104, 300-309, 2013.

Sutton, J. N., André, L., Cardinal, D., Conley, D. J., De Souza, G. F., Dean, J., Dodd, J., Ehlert, C., Ellwood, M. J., Frings, P. J., and Grasse, P.: A review of the stable isotope bio-geochemistry of the global silicon cycle and its associated trace elements, Front. Earth Sci., 5, 112, https://doi.org/10.3389/feart.2017.00112, 2018.

Tatzel, M., von Blanckenburg, F., Oelze, M., Bouchez, J., and Hippler, D.: Late Neoproterozoic seawater oxygenation by siliceous sponges, Nat. Commun., 8, 621, https://doi.org/10.1038/s41467017-00586-5, 2017.

Tesson, B. and Hildebrand, M.: Extensive and intimate association of the cytoskeleton with forming silica in diatoms: control over patterning on the meso-and micro-scale, PLoS One, 5, e14300, https://doi.org/10.1371/journal.pone.0014300, 2010.

Thamatrakoln, K. and Hildebrand, M.: Analysis of Thalassiosira pseudonana silicon transporters indicates distinct regulatory levels and transport activity through the cell cycle, Eukaryot. Cell, 6, 271-279, https://doi.org/10.1128/EC.00235-06, 2007.

Thamatrakoln, K. and Kustka, A. B.: When to say when: can excessive drinking explain silicon uptake in diatoms?, Bioessays, 31, 322-327, https://doi.org/10.1002/bies.200800185, 2009.

Tréguer, P., Bowler, C., Moriceau, B., Dutkiewicz, S., Gehlen, M., Aumont, O., Bittner, L., Dugdale, R., Finkel, Z., Iudicone, D., 
and Jahn, O.: Influence of diatom diversity on the ocean biological carbon pump, Nat. Geosci., 11, 27-37, 2018.

Tréguer, P. J. and De La Rocha, C. L.: The world ocean silica cycle, Annu. Rev. Mar. Sci., 5, 477-501, 2013.

Varela, D., Pride, C., and Brzezinski, M.: Biological fractionation of silicon isotopes in Southern Ocean surface waters, Global Biogeochem. Cy., 18, GB1047, https://doi.org/10.1029/2003GB002140, 2004.
Wenzl, S., Hett, R., Richthammer, P., and Sumper, M.: Silacidins: Highly acidic phosphopeptides from diatom shells assist in silica precipitation in vitro, Angew. Chem.-Int. Edit., 47, 1729-1732, https://doi.org/10.1002/anie.200704994, 2008.

Wille, M., Sutton, J., Ellwood, M. J., Sambridge, M., Maher, W., Eggins, S., and Kelly, M.: Silicon isotopic fractionation in marine sponges: A new model for understanding silicon isotopic variations in sponges, Earth Planet. Sc. Lett., 292, 281-289, 2010. 